\title{
A Structural Equation Model of the Impact of New Product Development on Competitive Advantage
}

\author{
Sanaz Soltani ${ }^{1,2}$, Esmaeel Ramazanpoor ${ }^{1} \&$ Seyedhadi Eslamian ${ }^{2}$ \\ ${ }^{1}$ Faculty of Literature and Humanities, University of Guilan, Rasht, Iran \\ ${ }^{2}$ Department of Management, Faculty of Humanities, University College of Nabi Akram (UCNA), Tabriz, Iran \\ Correspondence: Sanaz Soltani, Department of Management, Faculty of Humanities, University College of Nabi \\ Akram (UCNA), Tabriz, No. 1283, Rah Ahan st., Iran. Tel: 98-411-442-1999. E-mail: \\ soltani_management@yahoo.com
}

Received: March 17, 2014 Accepted: April 21, $2014 \quad$ Online Published: April 28, 2014

doi:10.5539/emr.v3n1p99 URL: http://dx.doi.org/10.5539/emr.v3n1p99

\begin{abstract}
Nowadays most organizations are looking to find the potentials for creating competitive advantages. The ability to develop new products is among the capability benefits and it's also the central point in contesting for many industries and in fact new products develop more and therefore there is more profits and create a competitive advantage for companies. This assay is to study the relationship between new product and the competitive advantage in chosen food industries of East Azarbayjan Province.

The conceptual prototype of this research (relationship between any development in products and competitive advantage dimensions) is prepared based on theoretical and experimental studies and it is followed by a suitable questionnaire to evaluate and measure the variables of study. After the validity and stability was confirmed, the questionnaire was distributed in the statistical sample (Selected food industries managers of Azarbayjan Province) and the selected data was put into the SPSS and LISREL software and those data were analyzed. The statistical data shows that the development of products both (gradual and integral), have a noticeable influence on competitive advantages. Innovation in products with improvement in quality, increase in proficiency, answering the customers and flexibility increase the competitive power of the company and provides a better position in the market for it.
\end{abstract}

Keywords: developing new product, competitive advantage, structural equations, LISREL

\section{Introduction}

To response to environmental changes in an appropriate manner, companies suspend or modify production or supply of some products. In addition, in order to identify and supply costumers' demands in different markets and to launch long term business and increase commercial outcomes, the companies develop new products. New product development is term used to describe a complete process to achieve a new product, a process beginning from ideas and ending to commercial exploitation of the new product. Companies have to modify previous products or even develop new products not only for improvement but also for survival in the competitive environment; so that developing new products with superior quality, reduced cost and time (from designing to reaching marketplace) assures costumers' satisfaction and profitability. It is obvious that all companies tend to retain their profitability in mature phases, by the way by which they can achieve this goal is the matter of question. New product development is a substantial approach for company survival in competitive market.

\section{Problem Statement}

Change is a pivotal factor that dominates competitive environment. The lifetime of a product is rather short and by new value added to the product by competitors and reduction of production cost, the price of older product is lost. Although the outcome of failure for introducing new product is too exorbitant for the companies (according to Sirpiski, failure rate for new products introduced in west market is shockingly as high as 35-45\%), introducing new products is a way to achieve competitive advantage. In other words, products variation and developing new products can improve company contribution in market, provide costumers' satisfaction and create competitive advantages on one hand; and on the other hand, generates critical challenges for the company by complicating 
official structure and increasing unpleased bureaucracy. The main goal of the present study is to explain the bilabial consequences of introducing new product and investigate the subject through a field study.

\section{New Product Development}

According to handbook of Product Development and Management association, new product development is defined as: a set of regular and predefined duties, steps and procedures describing the natural goal of the company to change the immature (primary) ideas in to marketable products and services. According to this definition, NPD process includes some subcultures (subsidiary processes) and sub-steps.

In a broad sense definition, new product development (NPD) is considered as a process for developing a new product which is different from previous and present products, in this manner, NPD is a kind of innovation (product innovation) in which new and distinct products are described and the word "product innovation" implicates recency and novelty.

Product development, according to Mormon and Miner (1997), is categorized in to two groups as fundamental development and gradual development; a classification based on the rate of changes and novelty of the product. Fundamental development refers to basic and substantial changes, whereas gradual development concerns with minor changes in technical dimensions of production which improve already existing products and services.

\section{Investigational Movement in the Field of NPD}

\subsection{Causative Approach}

This approaches aims at identifying success factors of some firms in NPD and offering solution to improve the NPD performance based on these results. This approach behaves as a "grey box" in relation to NPD process and investigates small fragments of the whole process. Therefore, this approach does not investigate whole the process systematically, rather searches for the main causes and methods considered as NPD determinants (for failure/ success).

Prominent works in this field have been performed by Cooper (1979), Clarck (1991), Marquiz (1969), Rothwell et al. (1974), the outcome of this approach is a list of failure/ success factors, problem solving methods relying on identified factors and so on.

\subsection{Cognitive Approach}

The goal of this approach is to offer some models, following their guidelines and instructions can result in NPD success. Prominent works in this field includes those carried out by bouse, alane, Hamilton (1982), cooper and Clanes Schmidt (1986, 1994), madwig and zirger (1990), etc. outcomes of this approach are various NPD graphical models and processes mainly classified in two distinct categories as linear (phase- review, stage-gate, etc) and nonlinear models (multi convergent and parallel models).

\subsection{Structure-Based Approach}

This approach aims at identifying the relationships existing in NPD variables and properties and understanding internal mechanism of NPD which facilitate achieving better outcomes. Indeed, in this approach NPD is regarded as evaluated properties of given variables based on created models. The works such as those performed by Gupta and Wilmone (1998) and Monaart et al., lie in this field.

\section{Competitive Advantage}

Competitive advantage is a factor or combination of factors making the organization superior over other organizations in a competitive environment and cannot be easily imitated by the competitors. Competitive advantage is the result of a consistent and dynamic process which, by regarding internal and external position of the organization, is rooted from organizational resources; by appropriate exploitation of these resources, capabilities are generated that can provide the organization with competitive advantages by suitable exploitation of these abilities.

To generate competitive advantage, two points should be considered: first, this is a protracted process resulting in organization competitiveness and superior performance. In other words, if the organization, using of its own competence, be able to generate stable competitive advantage which is superior to that of the competitors and worthy for the costumers, it generates a competent performance and competitiveness.

Second, due to increased environmental complexity and competitive severity, the generated competitive advantage is easily imitated by the competitors or loses its importance before the costumers; in this case, the competitive advantage should be replaced by new advantages. 
Based on this, the organization should stabilize its competitive advantages. To generate and sustain the competitive advantages, some competences are needed that, by means of organizational abilities, create value for costumers.

\section{New Product Development and Competitive Advantage}

Liand et al. (2010) investigated correlation between stable competitive advantage and innovation in Chinese companies and concluded that the innovation is influenced by various factors and their interaction and innovation is a new resource of the firm that results in stable competitive advantage and provides a holistic framework for performance improvement.

Porter (1985) claimed that technological changes are not important alone in terms of the relations between competitive advantage and innovation, rather it is important if can influence on competitive advantage and industrial structure. Scott kamis claimed that innovation is a necessity for company for creating and sustaining competitive position. In fact, successful firms consider innovation as a central part of their strategies.

\section{Methodology}

Concerning its goal this is an applied investigation and based on data gathering method, it is a descriptive- survey study. Statistical population includes all selected managers of food industry of Eastern Azerbaijan province. Likert scale was used to evaluate the relation between new product development and competitive advantage. The first section includes questions about general properties of the respondents, questions on new product development are dealt in section two, and the third section includes questions on competitive advantage. Questionnaire validity is of content validity type meaning that the content of the questionnaire was confirmed by supervisor and advisor professors and some academic and organizational experts. Reliability of the questionnaire was evaluated using cronbach's alpha and since the calculated value of cronbach's alpha $(86 \%)$ was higher than $70 \%$ it can be concluded that a suitable scientific basis for interpretation of the investigational results is provided. According to literature review, investigational hypotheses were set as the relationships between product development kinds (fundamental and partial) and competitive advantage dimensions including efficiency, quality, flexibility and response to costumers' demands. The hypotheses were evaluated by means of factor analysis using lisrel software.

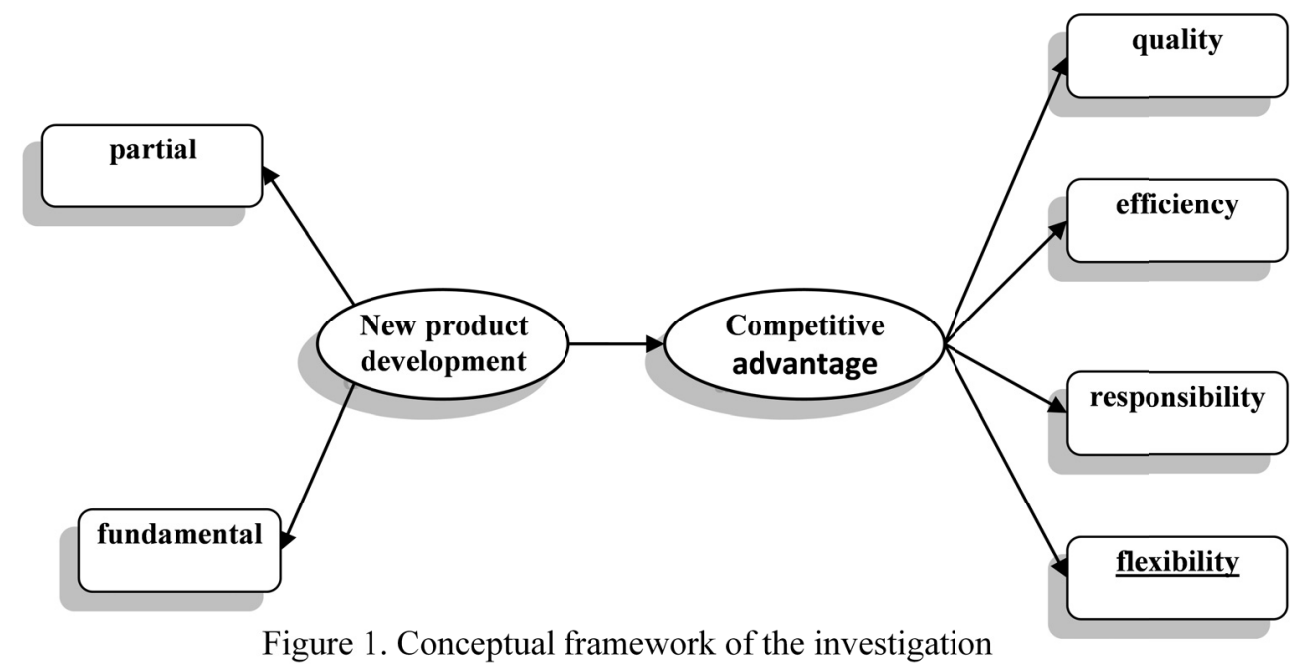

\section{Investigational Hypotheses Were Set as Follow}

- There is significant relation between new product development and improved competitive advantage.

- There is significant relation between dimensions of new product development and improved competitive advantage dimensions.

- $\quad$ There is significant relation between product fundamental development and efficiency.

- $\quad$ There is significant relation between product fundamental development and flexibility.

- $\quad$ There is significant relation between product fundamental development and quality.

- $\quad$ There is significant relation between product fundamental development and costumer satisfaction. 
- $\quad$ There is significant relation between product partial development and efficiency.

- $\quad$ There is significant relation between product partial development and flexibility.

- $\quad$ There is significant relation between product partial development and quality.

- There is significant relation between product partial development and costumer satisfaction.

\section{Confirmatory Factor Analysis of Applied Scales}

Results of factor analysis of evaluation indices of product development are presented in Table 1.

Table 1. Confirmatory factor analysis of evaluation scale of product development

\begin{tabular}{lccc}
\hline & Load factor & t statistic & Cronbach's alpha \\
\hline Evaluation indices of product & & & $0 / 900$ \\
fundamental development & $0 / 70$ & & \\
TB1 & $0 / 72$ & $9 / 48$ & \\
TB2 & $0 / 73$ & $1 / 91$ & \\
TB3 & $0 / 80$ & $11 / 61$ & \\
TB4 & $0 / 75$ & $10 / 55$ & \\
TB5 & $0 / 75$ & $10 / 56$ & \\
TB6 & $0 / 81$ & $11 / 64$ & \\
TB7 & & & \\
Evaluation indices of product & & & \\
fundamental development & $0 / 80$ & $11 / 39$ & \\
TJ8 & $0 / 59$ & $7 / 62$ & \\
TJ9 & $0 / 83$ & $12 / 01$ & \\
TJ10 & $0 / 70$ & $9 / 53$ & \\
TJ11 & $0 / 74$ & $10 / 12$ & \\
TJ12 & & \\
\hline
\end{tabular}

Note. $\mathrm{TB}=$ Fundamental Development; TJ=Partial Development.

Results of confirmatory factor analysis of evaluation indices of competitive advantage are presented in Table 2 .

Table 2. Confirmatory factor analysis of evaluation scale of competitive advantage

\begin{tabular}{lccc}
\hline & Load factor & t statistic & Cronbach's alpha \\
\hline Indices for evaluating quality factor & & & $0 / 811$ \\
Q13 & $0 / 71$ & $9 / 60$ & \\
Q14 & $0 / 61$ & $7 / 89$ & \\
Q15 & $0 / 78$ & $10 / 98$ & \\
Q16 & $0 / 77$ & $10 / 77$ & $0 / 841$ \\
Indices for evaluating flexibility factor & & & \\
E17 & $0 / 78$ & $11 / 06$ & \\
E18 & $0 / 77$ & $10 / 86$ & \\
E19 & $0 / 75$ & $10 / 58$ & \\
E20 & $0 / 73$ & $10 / 08$ & \\
Indices for evaluating responsibility factor & & & \\
P21 & $0 / 64$ & $8 / 42$ & \\
P22 & $0 / 77$ & $10 / 93$ & $0 / 868$ \\
P23 & $0 / 85$ & $12 / 69$ & \\
P24 & $0 / 83$ & $12 / 06$ & \\
Indices for evaluating efficiency factor & & & \\
K25 & $0 / 86$ & $12 / 61$ & \\
K26 & $0 / 83$ & $11 / 92$ & \\
K27 & $0 / 67$ & $11 / 57$ & \\
K28 & $0 / 81$ & & \\
\hline
\end{tabular}

Note. Q=Quality; E=Flexibility; $\mathrm{P}=$ Responsibility; K=Efficiency. 
Results of tables 1 and 2 indicate that appropriate items have been selected for evaluating dimensions of new product development and competitive advantage. In all cases, standard load factor was higher than 0.6 showing that observed relation is very favorable and only in one case it was calculated as 0.59 which is acceptable. $t$ statistic was calculated to assess observed standard load factors. In all cases, $\mathrm{t}$ value was higher than 1.96 indicating that the observed relations are acceptable $(\mathrm{p}<0.05)$.

\section{Hypothesis Tests Using Structural Equation Modeling}

Seven observable variables were used for evaluating product fundamental development construct. Competitive advantage in composed of four dimension (hidden variable) and for each hidden variable, four items (observable variable) were identified. Relation of product fundamental development with each dimension of competitive advantage as an observable variable is introduced in to the model.

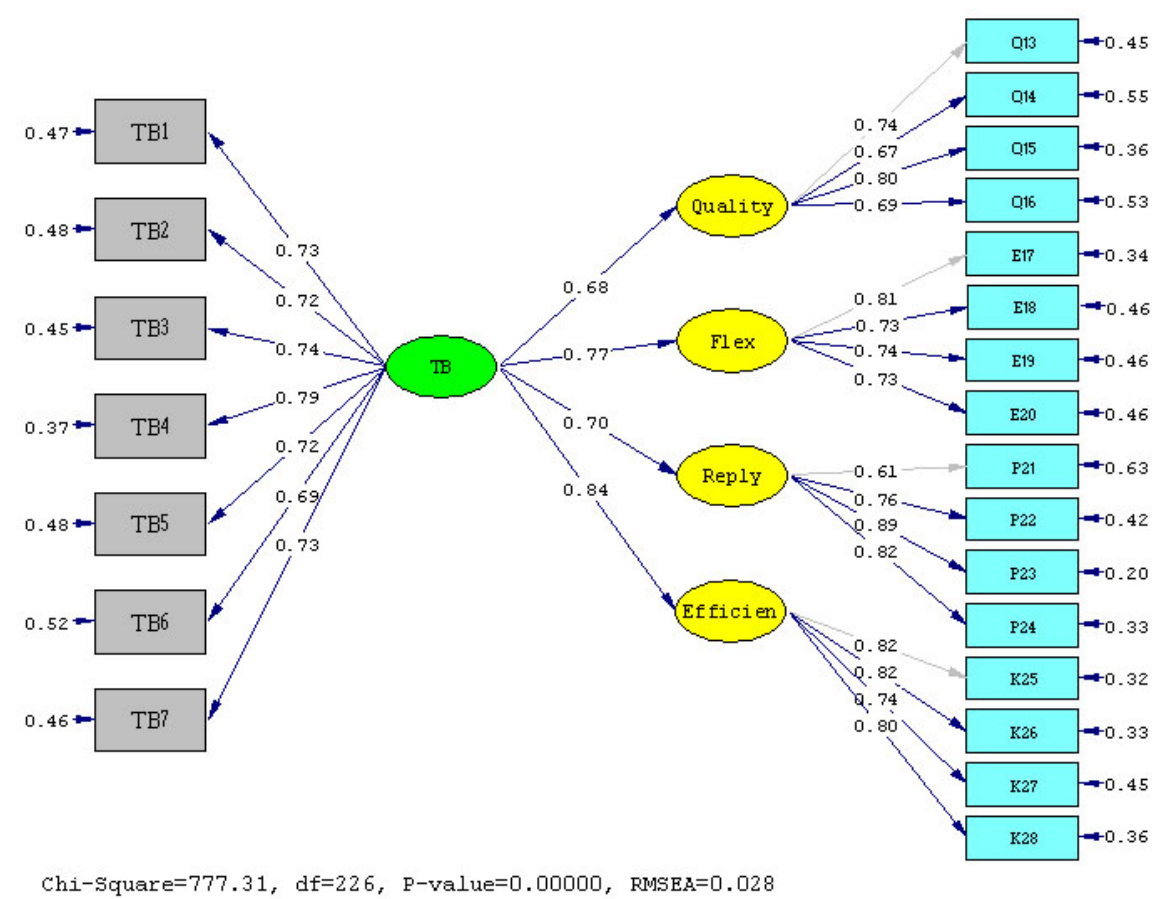

Figure 1. Standard load factor of the relation between product fundamental development with product competitive advantage

Note. TB=Fundamental Development; Flex=Flexibility; Q=Quality; Reply=Responsibility; Efficien=Efficiency; $\mathrm{E}=$ Flexibility; $\mathrm{K}=$ Efficiency; $\mathrm{P}=$ Responsibility.

Table 3. Summary of results of the relation between product fundamental development with product competitive advantage

\begin{tabular}{lccc}
\hline Relation & Standard load factor & t statistic & RMSEA \\
\hline FD Quality & $0 / 68$ & $6 / 93$ & $0 / 028$ \\
FD Flexibility & $0 / 77$ & $8 / 62$ & $0 / 028$ \\
FD Responsibility & $0 / 70$ & $6 / 33$ & $0 / 028$ \\
FD Efficiency & $0 / 84$ & $9 / 72$ & $0 / 028$ \\
\hline
\end{tabular}

Note. $\mathrm{FD}=$ Fundamental Development.

Calculated load factors show the relation between product fundamental development with quality, flexibility, responsibility about costumers' demands and efficiency suggesting good correlation between product fundamental development and each factor. Furthermore, the results show that the correlation is significant $(\mathrm{p}<0.05)$. According to these results, there is significant relation between product fundamental development with competitive advantage dimensions. 
To evaluate model fitness, some indices of goodness of fitness were used which are presented in table. Since RMSEA index was calculated lower than 0.1 , it can be concluded that model is well fitted. Other goodness of fitness indices were also placed in acceptable interval.

To evaluate the construct of partial development, five observable variables were used. Competitive advantage is composed of four dimensions (hidden variable) and to assess each hidden variable, four items (observable variable) were identified. Relation of product partial development with each dimension of competitive advantage as an observable variable is introduced in to the model.

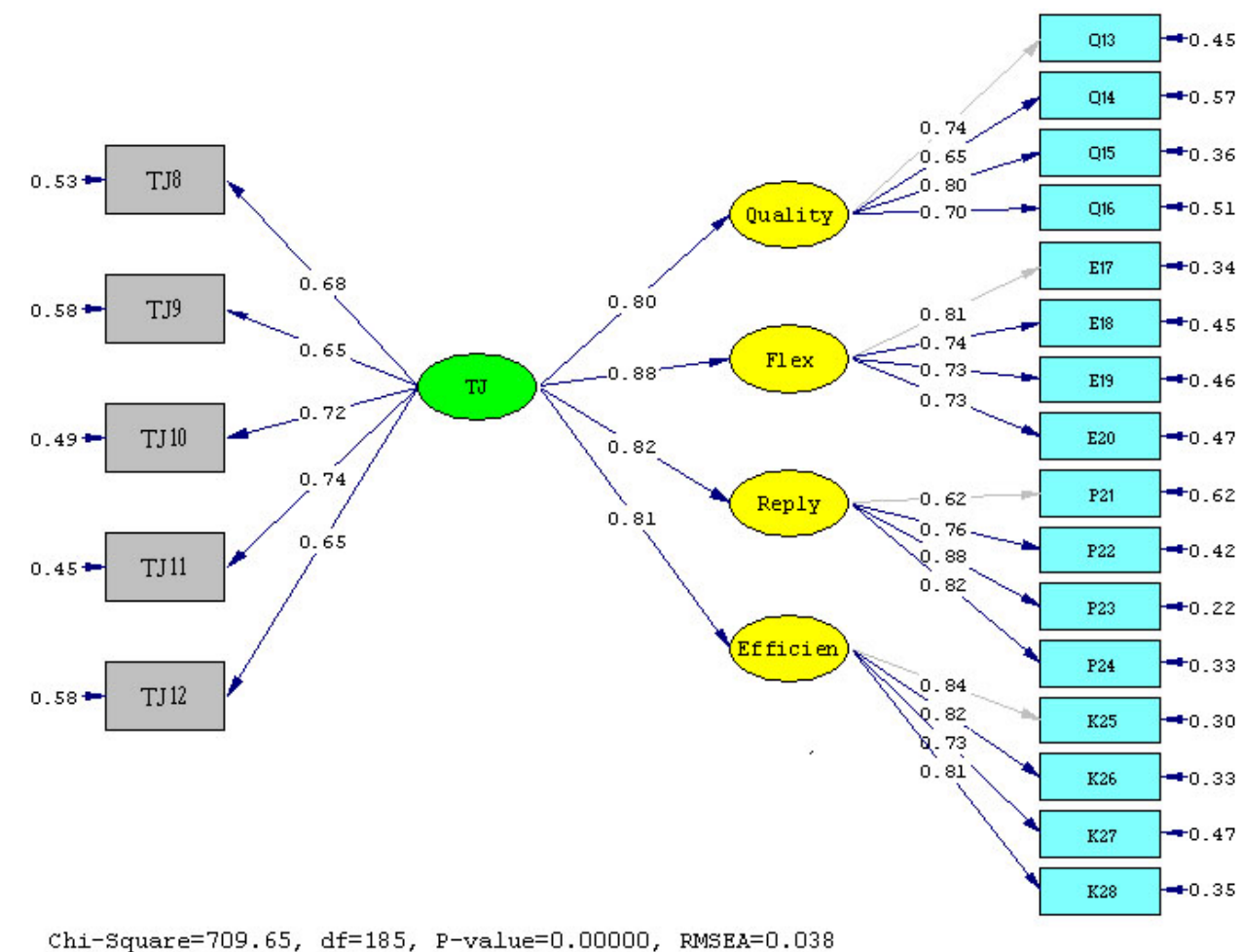

Figure 2. Standard load factor of the relation between product partial development with product competitive advantage

Note. TJ=Partial Development; Flex=Flexibility; Q=Quality; Reply=Responsibility; Efficien=Efficiency; $\mathrm{E}=$ Flexibility; $\mathrm{K}=$ Efficiency; $\mathrm{P}=$ Responsibility.

Table 3. Summary of results of the relation between product fundamental development with product competitive advantage

\begin{tabular}{lccc}
\hline Relation & Standard load factor & t statistic & RMSEA \\
\hline PD quality & $0 / 80$ & $8 / 08$ & $0 / 028$ \\
PD flexibility & $0 / 88$ & $9 / 99$ & $0 / 028$ \\
PD responsibility & $0 / 82$ & $7 / 08$ & $0 / 028$ \\
PD efficiency & $0 / 81$ & $9 / 47$ & $0 / 028$ \\
\hline
\end{tabular}

Note. $\mathrm{PD}=$ Partial Development.

Calculated load factors indicate the relation between product partial development with quality, flexibility, responsibility about costumers' demands and efficiency suggesting that there is good correlation between product partial development with each factor. Furthermore, the results show that the correlation is significant $(\mathrm{p}<0.05)$. Based on these results, there is significant relation between product partial development with competitive advantage dimensions.

To evaluate model fitness, some indices of goodness of fitness were used which are presented in table. Since RMSEA index was calculated lower than 0.1 , it can be concluded that model is well fitted. Other goodness of fitness indices were also placed in acceptable interval. 


\section{Final Model of the Investigation}

The main hypothesis of the investigation: there is significant relation between new product development and improvement of competitive advantage

In the final model of the investigation, the relation between product development construct and product competitive advantage construct was evaluated. For product development construct, two hidden variables including product fundamental development and product partial development were used. Each hidden variable is composed of a number of items. Average value of items used for evaluation of each hidden variable was calculated and as a result, two observable variables namely product fundamental development and product partial development were introduced in to the final model. Similarly, average values of the items used for assessing each variable of competitive advantage evaluation were calculated and these variables including quality, flexibility, responsibility and efficiency were introduced in to the final model as an observable variable.

In this model drawn using lisrel software output, load factors of evaluation of each competitive advantage dimension is indicated. Load factors of t-value statistic in each hypothesis show significance of the observed correlations. Load factors were calculated higher than 0.6 confirming that the dimensions used for evaluation of competitive advantage are selected appropriately and the model is confirmed. Furthermore, load factor of the correlation between competitive advantage and product development was calculated as 0.9 suggesting high correlation between the two constructs. Load factor of $t$ statistic was calculated 9.22 showing significance of the correlation.

To evaluate the fitness of final model, some indices of goodness of fitness were used. RMSEA index was calculated equal to 0.024 which is lower than 0.1. Moreover, other indices of goodness of fitness were also placed in acceptable interval. Therefore, the model is well fitted and investigational findings are reliable.

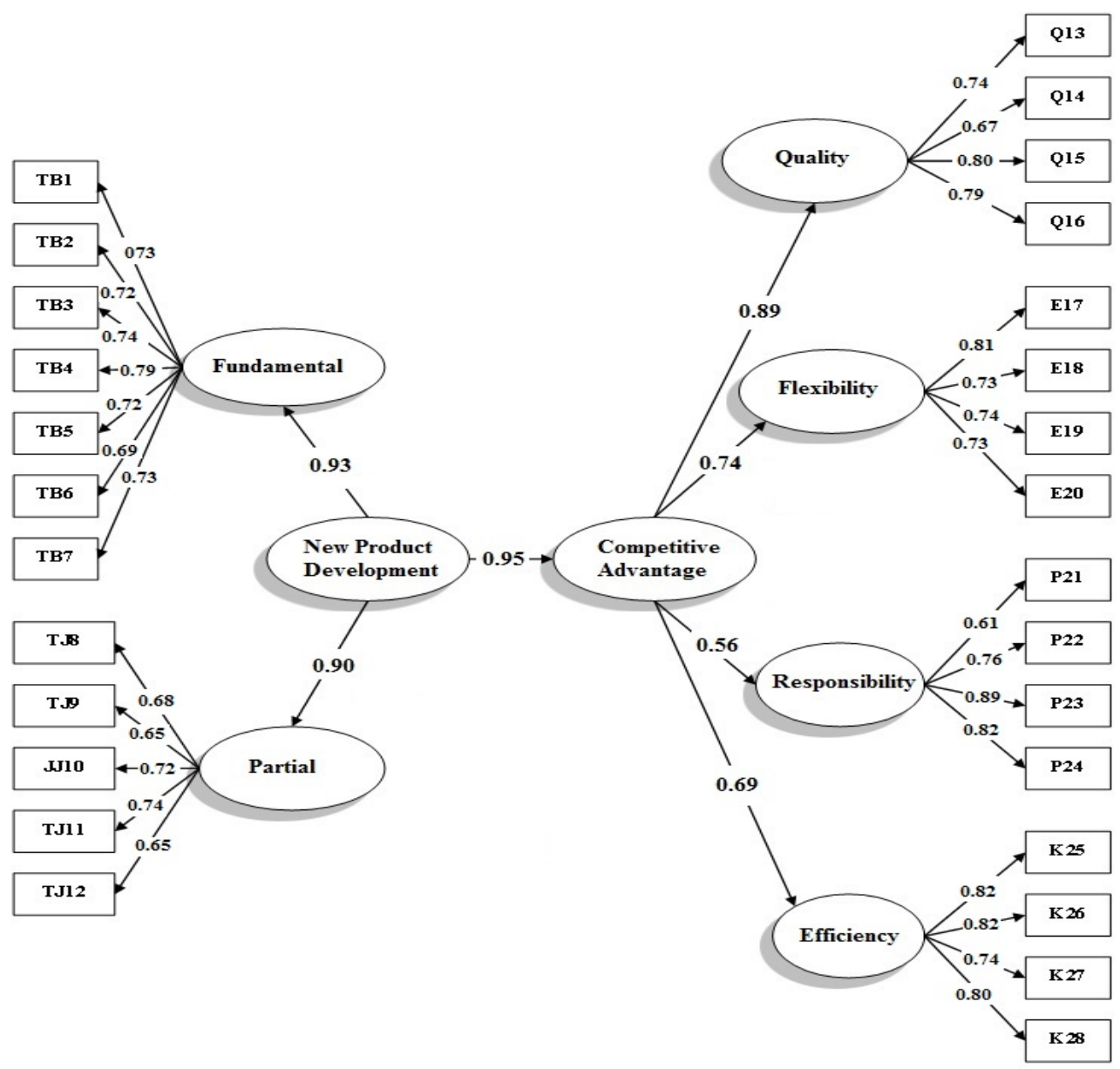

Figure 3. Results of final model confirmation

Note. TB=Fundamental Development; TJ=Partial Development; Q=Quality; E=Flexibility; P=Responsibility; $\mathrm{K}=$ Efficiency. 


\section{Suggestions}

New product development and its role in creating competitive advantage is an important issue which should be more seriously considered, because competition is the most important determinant in food industry due to saturation of present market. These issues are suggested to firms involved in food industry:

According to results of the first four hypotheses (effect of product fundamental development on competitive advantage) industrial managers can consider these cases to minimize the risk:

- identify costumers' demands through consistent marketing investigations and start production according to costumers' demands

- elucidate concept and importance of new products for all of the employees

- $\quad$ accept the suggestions about new changes

- pay attention to environmental changes

- Organization tendency to research and development

- According to results of the second four hypotheses (effect of product gradual development on competitive advantage), these suggestions are offered to managers to create distinction from competitors' products:

- Packaging variation

- Searching for new ideas for product development

- Using new forms of designing

- Use of stylistics and aesthetics

\subsection{Suggestions for Future Works}

These subjects are suggested to the students who want to carry out investigation in this field:

- investigating new product development and its influence on competitive advantage in high technology industry

- investigating new product development and its influence on firm contribution in market

- achieving competitive advantage using new product development.

- investigating various dimensions of competitive advantage in different firms and comparing them in term of their contribution in market

\section{Conclusion}

The results obtained in this study show that new product development is a key factor in achieving competitive advantage for food industry of Eastern Azerbaijan. After designing the model describing the relation between product development and dimensions of competitive advantage, an appropriate questionnaire was prepared by reviewing literature on dimensions of product development and competitive advantage and its validity and reliability were controlled using different ways. The questionnaire data was analyzed by factor analysis which is sophisticated and powerful technique using Lisrel software. Results show that both fundamental and partial kinds of product development lead to increase of quality, efficiency, flexibility and responsibility; so companies can follow innovation and new product development as a strategy to increase efficiency and costumers' satisfaction. Managers should, therefore, pay more attention to new product development and this attention will improve their performance for existing and potential costumers which ultimately result in increase of costumers' satisfaction and loyalty.

\section{Refrences}

Akimova, I. (2000). Development of market orientation and competitiveness of Ukrainian firms. European Journal of Marketing, 34(9/10), 1128-1148. http://dx.doi.org/10.1108/03090560010342511

Barney J. (1992). Firm Resources and Sustanined Competitive Advantage. Journal of Management, 17(1), 99-120. http://dx.doi.org/10.1177/014920639101700108

Brazell, J., Devinney, T., \& Midgley, D. (1998). Modeling the Three C's: A Multiple Choice Experiment Approach (pp. 1-38). University of Sydney.

Fahy, J., \& Smithee A. (1999). Strategic Marketing and the Resource Based View of the Firms (p. 10). Academy of Marketing Science Review. 
Feurer, R., \& Chaharbaghi, K. (1995). Strategy Development: past, present and future. Management Decision, 33(6), 58-70. http://dx.doi.org/ 10.1108/09684879710167647

Hax, C. A., \& Wilde, L. D. (2002). The delta model - toward a unified framework of strategy (pp. 4261-4262). MIT Sloan School of Management, WP. http://dx.doi.org/10.2139/ssrn.344580

Hill, C. W. L., \& Jones, G. R., (1998). Strategic Management Theory. Houghton Mifflen Com (2nd ed., pp. 105-127). USA.

Li, S., Bhanu Ragu-Nathan, T. S., \& SubbaRao, S. (2004). The impact of supply chain management practices on competitive advantage and organizational performance. The International Journal of Management Science. http://dx.doi.org/10.1016/j.omega.2004.08.002

Liu, S. S., Luo, X., \& Shi, Y. (2003). Market-oriented organizations in an emerging economy: a study of missing links. Journal of Business Research, 56(6), 481-491. http://dx.doi.org/10.1016/S0148-2963(01)00265-X

Lovelock, C., \& Wright, L. (2002). Principles of service marketing and management (2nd ed.). NewYork: McGraw-Hill.

McNaughton, B. R., Osborne, P., \& Imire, C. B. (2002). Market-oriented value creation in service firms. European Journal of Marketing, 36(9/10), 990-1002. http://dx.doi.org/10.1108/03090560210437299

Menguc, B., Auh, S., \& Shih, E. (2007).Transformational leadership and market orientation: Implications for the implementation of competitive strategies and business unit performance. Journal of Business Research, 60(4), 314-321. http://dx.doi.org/10.1016/j.jbusres.2006.12.008.

Porter, M. E. (1996). What is strategy?. Harvard Business Review, Nov.-Dec., 61-78.

Prahalad, C. K., \& Gary, H. (1990). The Core Competence of the Corporation. Harvard Business Review, 68, 79-91.

Garth, S., Shepard, A., \& Podolny, J. (2001). Strategic Management. John Wiley \& Sons, New York.

Sharkie, R. (2003). Knowledge creation and its place in the development of sustainable competitive advantage. Journal of Knowledge Management, 7(1), 20-31. http://dx.doi.org/ 10.1108/13673270310463590

Sharma, B., \& Gadenne, D. (2001). An investigation of the perceived importance and effectiveness of quality management approaches. The TQM Magazine, 13(6), 433-445. http://dx.doi.org/10.1108 /EUM0000000006180

Shurchuluu, P. (2002).National productivity and competitiveness strategies for the new millennium. Integrated Manufacturing Systems, 13(6), 408-414. http://dx.doi.org/10.1108/09576060210436650

Sirvastava, K. R., Fahey, L., \& Christensen, K. H. (2001). The resource-based view and marketing: the role of market-based assets in gaining competitive advantage. Journal of Management, 27(6), 777-802. http://dx.doi.org/10.1177/014920630102700610

Smith, S. (1995). World-Class Competitiveness. Managing Service Quality, 5(5), 36-42. http://dx.doi.org $/ 10.1108 / 09604529510100387$

Weerawardena J., \& O'cass, A. (2003). Exploring the characteristics of marketing - driven firms and antecedents to sustained competitive advantage. IndustrialMarketing Management, 33(5), 419-428. http://dx.doi.org/10.1016/j.indmarman.2003.07.002

Barney, J. B. (1999). Firm resources and sustained competitive advantage. Journal of Management, 17(1), 99-120. http://dx.doi.org/10.1177/014920639101700108

De Toni, A., \& Tonchia, S. (2003). Strategic planning and firms' competencies: Traditional approaches and new perspectives. International Journal of Operations \& Production Management, 23(9), 947-976. http://dx.doi.org/10.1108/01443570310491729

Harmsen, H., \& Jensen, B. (2003). Identifying the determinants of value creation in the market: A competence-based approach. Journal of Business Research, 57(5), 533-547. http://dx.doi.org/10.1016 /S0148-2963(02)00319-3

Lado, A. A., \& Zhang, M. J. (1998). Expert Systems, Knowledge Development and Utilization, and Sustained Competitive Advantage: A Resource-Based Model. Journal of Management, 24(4), 489-509. http://dx.doi.org/10.1016/S0149-2063(99)80070-1 
Morgan, R. M., \& Hunt, S. (1998). Relationship-Based Competitive Advantage: The Role of Relationship Marketing in Marketing Strategy. Journal of Business Research, 46(3), 281-290. http://dx.doi.org/10.1016/S0148-2963(98)00035-6

\section{Copyrights}

Copyright for this article is retained by the author(s), with first publication rights granted to the journal.

This is an open-access article distributed under the terms and conditions of the Creative Commons Attribution license (http://creativecommons.org/licenses/by/3.0/). 